\section{ENFERMAGEM E A DANÇA NA PROMOÇÃO A SAÚDE: VIVÊNCIA COM ADOLESCENTES EM VULNERABILIDADE SOCIAL}

\section{NURSING AND DANCING IN HEALTH PROMOTION: EXPERIENCES WITH ADOLESCENTS LIVING IN SOCIAL VULNERABILITY}

Ayeixa Victória Simões Carvalho ${ }^{1 /}$ Brenda Cardoso Carvalho ${ }^{1 /}$ Ingled Lorrayne Ramos da Silva ${ }^{1, *} /$ Lucielio dos Santos Xavier / Tatiana Barreto Pereira Viana ${ }^{1}$

\section{INTRODUÇÃO}

A adolescência, segundo a Organização Mundial da Saúde (OMS), é uma fase de transição que se estende dos dez aos vinte anos de idade. Entretanto, o Estatuto da Criança e do Adolescente (ECA), através da Lei 8.069, entende o adolescente como o indivíduo que possui faixa etária entre os 12 e 18 anos incompletos, havendo, em casos expressos por lei, a extensão até os 21 anos de idade (BRASIL, 1990).

Para Eisenstein (2005), esse período de transição, entre infância e idade adulta, é marcado:

“[...] pelos impulsos do desenvolvimento físico, mental, emocional, sexual e social e pelos esforços do indivíduo em alcançar os objetivos relacionados às expectativas culturais da sociedade em que vive". (EISENSTEIN, 2005, p. 6)

Essas transformações interferem direta ou indiretamente no comportamento dos adolescentes, bem como na sua expressão frente a sociedade (PESSALACIA; MENEZES; MASSUIA, 2010).

Estudos realizados em 2010, sobre a vulnerabilidade social da adolescência brasileira, mostram que, parte da população adolescente do nosso país, se encontram em situação de risco pessoal e social, "apresentando necessidades múltiplas e complexas, cujo atendimento exige um extenso elenco de programas e políticas de atenção à saúde dos mesmos" (PESSALACIA; MENEZES; MASSUIA, 2010).

\section{RESUMO}

A adolescência é uma fase de transição onde ocorrem mudanças que interferem, direta ou indiretamente, na vida dos indivíduos, especialmente naqueles em risco de vulnerabilidade social. Assim sendo, deve-se oportunizar à esse público as informações necessárias que garantam, entre outros benefícios, o estímulo para autocuidado. Nesse contexto, a educação em saúde, embasada nas metodologias ativas que associam recursos prazerosos, como a dança, na aplicação prática dos assuntos, favorece para melhor assimilação e adesão das temáticas por parte dos adolescentes Objetivo: descrever a experiência de uma oficina de dança com adolescentes em risco de vulnerabilidade social. Materiais e Métodos: estudo de caráter descritivo, relata a experiência de um Projeto de Extensão com 20 adolescentes que participam do Serviço de Convivência e Fortalecimento de Vínculo. Resultados: os adolescentes perceberam a importância da dança para além de seu papel divertido, observando que a mesma apresenta aspectos culturais, educacionais e sociais fundamentais para a formação individual e coletiva nessa etapa da vida. Conclusão: assim sendo, conclui-se que a dança, por seu papel educacional, é um recurso ideal para discussão de temáticas relacionadas à saúde, devendo por isso ser inserida no contexto de educação em saúde, especialmente dos adolescentes em risco de vulnerabilidade social.

Palavras-chave: Enfermagem. Adolescência. Educação em Saúde.

\section{ABSTRACT}

Adolescence is a transition phase where changes occur that directly or indirectly interfere in the lives of individuals, especially those at risk of social vulnerability. Therefore, this public must be given the necessary information to ensure, among other benefits, the incentive for self-care. In this context, health education, based on active methodologies that combine pleasurable resources, such as dance, in the practical application of subjects, favors for better assimilation and adherence of themes by adolescents Objective: to describe the experience of a dance workshop with adolescents at risk of social vulnerability. Materials and Methods: a descriptive study, reports the experience of an Extension Project with 20 adolescents who participate in the Service of Strengthening and Bonding. Results: the adolescents realized the importance of dance in addition to its fun role, observing that it has fundamental cultural, educational and social aspects for individual and collective formation in this stage of life. Conclusion: therefore, we conclude that dance, due to its educational role, is an ideal resource for discussing health-related topics, and should therefore be inserted in the context of health education, especially for adolescents at risk of social vulnerability.

Keywords: Nursing. Adolescence. Health education.

${ }^{1}$ Universidade do Estado da Bahia - UNEB, Guanambi, Bahia - Brasil.

E-mail para correspondência: damacedo@uneb.br

Rev. ComCiência - jun. 2020, vol. 5, no. 6, p. 104-107/ doi: 10.36112/ issn2595-1890.v5.i6.p104-107 
O conceito de vulnerabilidade para Brêtas (2010), deve ser entendido como resultante de um conjunto de aspectos individuais e coletivos, que acarretam maior suscetibilidade à infecção e ao adoecimento e, de modo inseparável, maior ou menor disponibilidade de recursos de todas as ordens para se proteger de ambos. Para Fonseca et al. (2013), na ótica da adolescência, essa vulnerabilidade remete à ideia de fragilidade e de dependência, principalmente nos adolescentes de menor nível socioeconômico.

$\mathrm{Na}$ adolescência, os indivíduos tendem a viver uma constante busca pela real personalidade, manifestando comportamentos extremos e diversificados, sendo, em determinados momentos, negligentes com os cuidados à saúde (FONSECA et al. 2013).

Para Costa et al. (2004), o processo de educação em saúde deve ser entendido como meio de "preparar o homem para a preservação de seu bem-estar biopsicossocial”. Essa afirmativa aponta que o processo educativo é uma reflexão de mudanças de atitude, desse modo, ao desenvolver educação em saúde com adolescentes, os profissionais de enfermagem atuam diretamente nos conceitos pessoais de bem-estar, criando ambiente de análise sobre os estilos de vida de cada ser. (COSTA et al. 2004).

O enfermeiro é, por si só, um educador social e, tendo a enfermagem o papel de proporcionar uma assistência holística, cabe aos profissionais, apropriar-se de diversos mecanismos para garantir a promoção e a prevenção da saúde, o bem-estar e o cuidado humano (MARBÁ; SILVA; GUIMARÃES, 2016).

A enfermagem, sendo compreendida enquanto arte e ciência do cuidar, atua na restauração da dignidade do corpo em todos os âmbitos da vida
(COSTA et al. 2004). Para além disso, Costa et al., salientam ainda que é necessário entender a enfermagem não apenas enquanto ciência, já que "utiliza da arte como um recurso de restauração do processo de assistência ao ser humano através da promoção da saúde e seus processos educativos" (COSTA et al. 2004).

A dança surge nesse contexto da arte, da enfermagem e da educação em saúde, como recurso que possibilita o desenvolvimento do raciocínio rápido e lógico dos seus praticantes, através dos movimentos rítmicos e coordenados da musculatura corporal (MARBÁ; SILVA; GUIMARÃES, 2016). De acordo Costa et al. (2004), "a dança permite sentir, de modo mais ampliado, a necessidade de saúde corporal em um indivíduo"; tendo na adolescência um papel ainda mais significativo, haja vista as inúmeras transformações corporais, psíquicas e sociais que ocorrem nessa fase da vida.

$\mathrm{O}$ processo de mudança de comportamento, especialmente nos adolescentes, apresenta mais resultados se estiver associado ao prazer e ao gostar. A dança, por sua característica prazerosa e divertida, constitui-se então, como recurso educacional ideal para a promoção da saúde, sendo aplicada em várias Organizações nãogovernamentais (ONG's) pelo Brasil (COSTA et al. 2004).

A promoção da saúde dos adolescentes tornou-se uma temática muito debatida atualmente e têm apresentado inúmeras preocupações para os profissionais de saúde, especialmente no intuito de provocar nesse público o interesse pelo autocuidado (MARBÁ; SILVA; GUIMARÃES, 2016).

Diante do exposto, visa-se descrever a experiência de uma oficina de dança como recurso educacional na abordagem temática sobre higiene corporal e ambiental, na promoção da saúde de adolescentes em risco de vulnerabilidade social, que participam de um Serviço de Convivência e Fortalecimento de Vínculos.

\section{MATERIAIS E MÉTODOS}

\section{Processo metodológico na execução da atividade extensionista}

Este estudo é de caráter descritivo e relata a experiência de um Projeto de Extensão financiado pela PROEX/UNEB, intitulado "Projeto de Extensão Interdisciplinar em Atenção Integral a Saúde do Adolescente" do curso de Enfermagem da Universidade do Estado da Bahia, Departamento de Educação, Campus XII realizado em parceria com a Secretaria Municipal de Assistência Social no município localizado no Alto Sertão Produtivo.

O local selecionado para o desenvolvimento deste projeto é uma sede do Serviço de Convivência e Fortalecimento de Vínculo, localizado em um bairro periférico no município de Guanambi. A escolha desse local decorreu após realização de um diagnóstico situacional, ocorrido em 2017 , onde percebeu-se que, dentre as demais sedes avaliadas, os adolescentes desta, apresentavam maiores déficits escolares e maior vulnerabilidade aos condicionantes sociais, tendo por esta razão maior necessidade de práticas educativas.

Os participantes do projeto compreendem uma média de 20 adolescentes, conforme os critérios etários do Estatuto da Criança e Adolescente. De acordo o documento do Sistema Único de Assistência Social (SUAS, 2017), no Serviço de Convivência e Fortalecimento de Vínculo (SCFV) os adolescentes devem ser assistidos de acordo as especificidades de cada um. 
O SCFV é um serviço da Proteção Social Básica do SUAS, regulamentado pela Tipificação Nacional de Serviços Socioassistenciais (Resolução CNAS n ${ }^{\circ}$ 109/2009), sendo, em 2013, reordenado por meio da Resolução CNAS no01/2013. Esse serviço, pautado no caráter preventivo e proativo, visa a defesa e afirmação de direitos e o desenvolvimento de capacidades e potencialidades dos usuários, buscando alternativas emancipatórias para o enfrentamento das vulnerabilidades sociais.

Para o Ministério do Desenvolvimento Social e Combate à Fome (MDS, 2017) deve-se ofertar o serviço "de modo a garantir as seguranças de acolhida e de convívio familiar e comunitário, além de estimular o desenvolvimento da autonomia dos usuários", considerando as especificidades dos ciclos de vida e contando com a participação ativa do técnico de referência, dos orientadores sociais e dos usuários.

A atividade desenvolvida pelo projeto ocorreu em uma quinta-feira no horário matutino, sendo este o dia e turno acordado previamente com a instituição para realização das intervenções do grupo. Na prática em questão foram abordadas as temáticas relacionadas à higiene corporal e ambiental.

A metodologia foi baseada em práticas educativas estruturadas no conjunto de atividades sistematizadas e operacionalizadas através das quais, foi desenvolvida a oficina e dinâmica em grupo. O processo educativo na promoção da saúde do adolescente, quando sistematizado, pode colaborar para a tomada de decisão, tanto individual quanto coletivamente, na perspectiva de uma vida saudável (GURGEL, 2010).
Esta metodologia se aplica ao propósito do projeto de extensão por proporcionar uma maior participação coletiva, criando espaços de diálogo, nos quais os sujeitos podem se expressar e, sobretudo realizar uma escuta ativa. Além disso, esta estratégia de atuação contribui para a construção da autonomia dos adolescentes, uma vez que estimula e motiva a problematização, a socialização de saberes e a reflexão voltada para a ação (SÃO PAULO, 2006).

Para a adequação dos conteúdos abordados na oficina, a dança foi selecionada como o recurso didático de modo criterioso, a fim de colaborar com a fixação das informações orientadas ao grupo de adolescentes.

A atividade foi construída em dois momentos descritos a seguir:

Inicialmente os adolescentes foram centralizados em um círculo, permitindo o maior contato entre os envolvidos e a fuga do modo tradicionalista de explicação de conteúdo. Nesse momento foram abordados, de maneira teórica, informações acerca do tema proposto para a referida oficina, que neste caso, tratava-se da higiene corporal e ambiental. Durante a explanação do conteúdo procurou-se sanar as dúvidas existentes entre os adolescentes, bem como estimulá-los a refletir sobre o cuidado com o meio onde vivem, uma vez que, como se sabe, a higiene do corpo também demanda do cuidado com o ambiente.

No segundo momento, instituiuse a dança como forma prática de aplicação dos conhecimentos adquiridos na parte teórica. A construção dos movimentos rítmicos foi baseada no objetivo de demonstrar o correto cuidado com o corpo, especialmente durante o banho e ao escovar os dentes.

\section{RESULTADOS E DISCUSSÕES}

Utilizando a revisão de literatura como meio de aprimorar o embasamento teórico aos resultados alcançados

No desenvolvimento da atividade da dança, percebeu-se um afastamento de parte do grupo participante, formado majoritariamente por meninos. A desistência do grupo em concluir a atividade foi justificada pelo "preconceito", existente em algumas falas, de que "dança é coisa de menina". As respostas dadas direcionaram a atividade para abordagem de uma nova temática voltada para a desconstrução da afirmativa de que dança tem sexo.

Segundo Feitosa e Pinto (2016), "uma das maiores dificuldades de implantar a dança no ensino escolar está relacionada à diferença de gênero". Nesse contexto os autores afirmam ser necessário diferenciar gênero e sexo, sendo que um é entendido como uma condição social de identificação entre masculino e feminino e o outro trata-se, respectivamente, apenas de diferenças biológicas.

Enquanto modalidade física a dança proporciona inúmeros benefícios, tais como resistência e força, redução do risco de doenças nos sistemas cardiovascular e locomotor, diminuição do sedentarismo e do índice de pressão arterial, além de proporcionar disposição para as atividades diárias e diversão, sendo por isso uma das atividades em crescimento no cenário atual da preocupação com o corpo. (MARBÁ et al.2016)

Para a pesquisadora Marbá et al. (2016), a dança deve ser entendida para além da atividade física, estando inserida no contexto cultural, educacional, religioso, e social. 
$\mathrm{Na}$ área da educação, a dança é entendida, segundo a mesma pesquisadora, "como um meio prático e ativo de abordar vários temas importantes, uma vez que possibilita, por meio do processo fazer-pensar, a construção e ampliação de conhecimentos acerca do mundo onde vivemos" (MARBÁ et al. 2016).

No contexto cultural, a prática da dança é compreendida como uma arte que permite a expressão das emoções por meio de uma manifestação natural e ritual humana. Já para a religião, a dança sempre esteve vinculada aos cultos de agradecimento, pedidos, preces, entre outros.

Do ponto de vista social a dança permite, através do movimento, a expressão e a comunicação necessária para a formação de um indivíduo crítico e racional, comprometido com a sociedade em que vive. (MARBÁ et al. 2016). Para além disso, a dança ainda contribui para o desenvolvimento de relações pessoais saudáveis ensinando, através disso, o viver em comunidade (EISENSTEIN, 2005), sendo assim, um recurso ideal por se aproximar dos objetivos dos Serviço de Convivência e Fortalecimento de Vínculos (SCFV).

Após a discussão, os adolescentes perceberam a importância da dança para além de seu papel divertido, observando que a mesma apresenta aspectos culturais, educacionais e sociais fundamentais para nossa formação individual e coletiva. Para além disso, a desconstrução da ideia de que a dança possui característica feminino e/ou masculina foi essencial para a retomada da atividade, bem como para a satisfação dos adolescentes envolvidos.

Portanto, o projeto apresenta-se como um espaço para o esclarecimento de dúvidas e uma oportunidade para reflexão acerca de alguns aspectos que circundam a adolescência.

\section{CONCLUSÃO}

Percepções e conclusões acerca das ações extensionistas

Assim sendo, diante dos inúmeros benefícios apresentados, a dança configura-se como um recurso ideal para a explanação de conteúdos relacionados a educação em saúde de adolescentes em risco de vulnerabilidade social.

O caráter educacional, cultural e social da dança, bem como suas características prazerosas e divertidas, facilita a troca de informações e o diálogo com os adolescentes, uma vez que, nessa fase, os mesmos sentem resistência em aceitar certas informações.

Os SCFV, bem como o referido projeto, desempenham um papel de suma importância na garantia de ações que estimulam os adolescentes quanto ao autocuidado, devendo por isso serem valorizados, especialmente por meio de recursos financeiros, que sustentem os espaços.

O profissional de enfermagem deve então, diante deste cenário, estar apto a adicionar a dança no contexto didático de abordagem dos conteúdos, uma vez que, através desse estudo, percebeu-se que os adolescentes desenvolveram, durante posteriores encontros, o interesse, a participação e a integração com o projeto, com a comunidade e com o espaço onde vivem, bem como melhor compreensão dos conteúdos trabalhados.

\section{REFERÊNCIAS}

BRÊTAS, José Roberto da Silva.

VULNERABILIDADE E ADOLESCÊNCIA. Rev. Soc. Bras.

Enferm. Ped., São Paulo, v. 10, n. 2, p.89-96, dez. 2010

COSTA, Anny Gm et al. A DANÇA COMO MEIO DE CONHECIMENTO DO CORPO PARA PROMOÇÃO DA SAÚDE DOS ADOLESCENTES. Dst - J Bras Doenças Sex Transm, Brasilia, v. 3, n. 16, p.43-49, 2004.

EISENSTEIN, Evelyn. Adolescência: definições, conceitos e critérios.

Adolescência e Saúde, Rio de Janeiro, v. 2, n. 2, p.6-7, jun. 2005.

FONSECA, Franciele Fagundes et al. As vulnerabilidades na infância e adolescência e as políticas públicas brasileiras de intervenção. Rev Paul Pediatria, Montes Claro, v. 31, n. 2, p.258-264, jan. 2013.

MARBÁ, Romolo Falcão; SILVA, Geusiane Soares da; GUIMARÃES, Thamara Barbosa. DANÇA NA PROMOÇÃO DA SAÚDE E MELHORIA DA QUALIDADE DE VIDA. Revista Científica do ITPAC, Araguaína, v. 9, n. 1, p.1-9, fev. 2016.

PESSALACIA, Juliana Dias Reis; MENEZES, Elen Soraia de; MASSUIA, Dinéia. A vulnerabilidade do adolescente numa perspectiva das políticas de saúde pública. Revista Bioethikos, São Camilo, v. 4, n. 4, p.423-430, jan. 2010.

PINTO, Celeida Belchior Garcia Cintra; FEITOSA, Roberta Pereira; PINTO, Celeida Belchior Garcia Cintra. O ensino da dança e a relação de gênero na educação básica.

Universitas: Ciências da Saúde, [s.l.], v. 15, n. 1, p.57-65, 26 jun. 2017.

Centro de Ensino Unificado de Brasilia. http://dx.doi.org/10.5102/ucs.v15i1.42 92. 